\title{
15-year efficacy of uvulopalatopharyngoplasty based on objective and subjective data
}

\author{
Nanna Browaldh, Danielle Friberg, Eva Svanborg and Pia Nerfeldt
}

\section{Linköping University Post Print}

N.B.: When citing this work, cite the original article.

Original Publication:

Nanna Browaldh, Danielle Friberg, Eva Svanborg and Pia Nerfeldt, 15-year efficacy of uvulopalatopharyngoplasty based on objective and subjective data, 2011, Acta OtoLaryngologica, (131), 12, 1303-1310.

http://dx.doi.org/10.3109/00016489.2011.616912

Copyright: Informa Healthcare

http://informahealthcare.com/

Postprint available at: Linköping University Electronic Press

http://urn.kb.se/resolve?urn=urn:nbn:se:liu:diva-72804 


\section{5-year efficacy of uvulopalatopharyngoplasty based on objective and subjective data}

\section{Abstract \\ Conclusions:}

This follow-up showed a stable and significant decrease in median oxygen desaturation index $4 \%\left(\mathrm{ODI}_{4}\right)$ values over the years. Approximately two thirds of the patients fulfilled the success criteria $\left(\mathrm{ODI}_{4}\right.$ reduction of $50 \%$ and < 20) after 15 years. A majority had improved/cured excessive daytime sleepiness (EDS) and was satisfied. No increased mortality rate was seen.

\section{Objectives:}

To evaluate sleep apnoea recordings and symptoms in patients with obstructive sleep apnoea syndrome 15 years after uvulopalatopharyngoplasty (UPPP) compared to baseline, and previous follow-ups.

\section{Method:}

A non-randomized, prospective intervention study on 50 patients who underwent UPPP during 1985-88. Their initial median age was 49 (range 38-71) and $\mathrm{ODI}_{4} 26.5$ (4-82). Results:

13 patients had died. 26 patients underwent sleep apnoea recordings. Median $\mathrm{ODI}_{4}$ had decreased from 26.5 (range 4-82) to $8.5(0-60)$, p $<0.01$, a mean reduction of $52 \% .65 \%$ achieved the success criteria. One third was objectively categorized as non-snorers. Median body mass index was unchanged. The questionnaires were answered by 32 of 37 patients. $88 \%$ reported improved or cured EDS, $78 \%$ were satisfied. Pharyngeal disturbances ratings were low. The standardized mortality rate did not differ from the general Swedish population. 
Keywords:

Sleep apnoea, Obstructive sleep apnoea (OSA), Obstructive sleep apnoea syndrome (OSAS), Uvulopalatopharyngoplasty (UPPP), Pharyngeal surgery. 


\section{Introduction}

Currently, the main treatment for obstructive sleep apnoea syndrome (OSAS) is a continuous positive airway pressure device (CPAP) and mandibular retaining devices (MRDs). An alternative treatment is uvulopalatopharyngoplasty (UPPP),(1) which was the dominant treatment before CPAP was generally available. In the mid-1980s when the patients in the present study were first seen, UPPP was practically the only available treatment for OSAS in Sweden. The role of UPPP has since then been questioned because of side effects and limited efficacy. In a recently published meta-analysis of 15 UPPP studies, only a $33 \%$ reduction in the apnoea-hypopnoea index (AHI) was found.(2) As there are very few randomized controlled studies, the level of evidence that UPPP can be effective as OSAS treatment is low. Also, there are a few long-term follow-up studies after UPPP; such studies have been called for because a decreasing effect over time has been suspected.(3)

The patients in the present study have previously been evaluated at 6 months, 2 and 4 years postoperatively regarding excessive daytime sleepiness (EDS) and renewed sleep apnoea recordings.(4)' (5) They showed significant decreases in the mean oxygen desaturation index of $4 \%\left(\mathrm{ODI}_{4}\right)$, but $50 \%$ of the patients were regarded as failures $\left(\mathrm{ODI}_{4}>20\right.$ with reduction < 50\%). Another long-term study on 34 patients by Janson et al.,(6) using stricter success criteria (AHI < 10 with reduction $>50 \%$ ), found that 52\% were failures 4-8 years after UPPP surgery. Side effects of the UPPP, with different aspects of pharyngeal disturbances, are reported.(7) However, in a recent questionnaire study of OSAS patients at our centre, there was no increase in the median pharyngeal symptom score one year after UPPP, compared to baseline.(8) The mortality results among UPPP-treated patients have been studied by Lysdahl and Haraldsson.(9) No increased mortality was found after UPPP in a 5 to 9-year follow-up of 
400 consecutive snorers, 256 of whom had OSAS, compared to a control population. Their results might indicate a positive survival effect of surgery. Otherwise, mortality studies on OSAS patients have indicated an approximately 3 times increased mortality rate.(10)' (11)

The aim of the present study was to evaluate the efficacy of UPPP treatment for OSAS after 15 years, the longest follow-up hitherto. The effects were measured objectively with sleep apnoea recordings as well as subjectively with questionnaires concerning patient overall satisfaction, daytime sleepiness, pharyngeal side effects, and snoring. The mortality rates of the original group of patients were calculated in comparison to the Swedish general population. 


\section{Materials and Methods}

Subjects: Fifty unselected consecutive patients with habitual snoring and subjective symptoms of OSAS, 48 men and 2 women, underwent UPPP between 1985 and 1988. The median age at inclusion was 49 years (range 38-71), median BMI 30 (20-43) and median $\mathrm{ODI}_{4} 26.5$ (4-82), Table I. Among the 50 patients, 8 had no EDS, 11 mild, 21 moderate and 10 severe EDS at baseline, according to a question to what degree they experienced subjective excessive daytime sleepiness. All patients but one fulfilled the nowadays criteria of OSAS according to American Academy of Sleep Medicine; respiratory disturbance index of 5 or more and typical symptoms. One patient with moderate EDS had a baseline $\mathrm{ODI}_{4}$ value of only 4 . However, as the patient had undergone all previous follow-ups, he was also included in this. Our clinical practice is to inform all patients of the importance of stable weight after surgery. All patients who had failed surgery were subsequently offered complementary treatment.

Method of uvulopalatopharyngoplasty: The patients underwent UPPP, including tonsillectomy using cold steel technique at the Department of Oto-Rhino-Laryngology at Söder Hospital in Stockholm. A small resection of the uvula was done, but all other muscles, including the palatopharyngeal muscle, were preserved. Single sutures were used to adapt the mucosal edges of the pillar arches after removal of the excessive mucosa.

15 year follow-up comprised ambulant sleep apnoea recordings during one night and questionnaires concerning EDS, satisfaction, and pharyngeal symptoms. 
Table I

Anthropometric data at baseline and results from preoperative sleep recordings for all patients, also divided into subgroups.

\begin{tabular}{|c|c|c|c|c|c|c|c|}
\hline Subgroup & All & $\begin{array}{c}\text { Filled in } \\
\text { questionnaires }\end{array}$ & $\begin{array}{c}\text { Drop-outs } \\
\text { uestionnaires }\end{array}$ & Living & Dead & $\begin{array}{c}\text { Sleep } \\
\text { recordings }\end{array}$ & $\begin{array}{l}\text { No sleep } \\
\text { recordings }\end{array}$ \\
\hline $\begin{array}{l}\text { Number of } \\
\text { patients (n) }\end{array}$ & $\mathrm{n}=50$ & $n=32$ & $n=5$ & $\mathrm{n}=37$ & $\mathrm{n}=13$ & $n=26$ & $\mathrm{n}=11$ \\
\hline Age & $49(38-71)$ & $48(38-64)$ & $57(43-63)$ & $48(38-64)^{*}$ & $57(43-71)$ & $47(38-64)$ & $52(38-63)$ \\
\hline BMI & $30(20-43)$ & $30(20-41)$ & $30(24-43)$ & $30(20-43)$ & $30(20-35)$ & $30(20-41)$ & $29(24-43)$ \\
\hline $\mathrm{ODI}_{4}$ & $26(4-82)$ & $25(4-82)$ & $31(6-60)$ & $26(4-82)$ & $27(6-69)$ & $27(4-82)$ & $26(6-60)$ \\
\hline Nadir $\mathrm{SaO}_{2} \%$ & $76(36-92)$ & $74(36-92)$ & $75(47-82)$ & $75(36-92)$ & $78(38-88)$ & 77 (36-92) & $72(47-83)$ \\
\hline
\end{tabular}

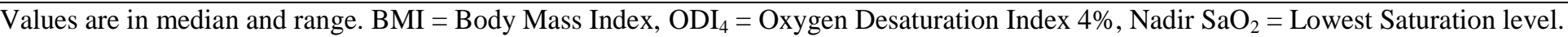

$*=\mathrm{p}<0.05$ significant difference in age (MWUT). 
Sleep apnoea recordings: Whole-night recordings were made in the patients' homes, using the same equipment and approach as at baseline and at the previous follow-ups. Patients who used additive treatment (CPAP or MRD) did not use it during the night of the sleep recording. The recordings comprised respiratory and body movements, body position, ear oximetry, and sound $(\mathrm{dB})$ measurements using the digitized Apnolog system (C-A Tegner Inc., Stockholm, Sweden). The oximetry and dB levels were scored using the Apnolog software. Sleeping time was manually estimated from the movement recording by one of the investigators (E.S.), who was blinded to the patient's subjective symptoms. The percentage of the estimated total sleep time (TST) during which respiratory sounds exceeded $40 \mathrm{~dB}$ was calculated, and if the time was above $40 \%$, the patient was objectively classified as a snorer.

Success criteria of sleep apnoea recordings: $\mathrm{ODI}_{4}<20$ and reduction of at least $50 \%$ compared to baseline. No more than 10 desaturations below $90 \%$ during 6 hours of sleep.

\section{Distributed questionnaires:}

A. Questionnaire concerning satisfaction, EDS, and subjective snoring. The questions were: "Are you satisfied with the UPPP surgery?"(Yes/No), "Do you regret the UPPP surgery?" (Yes/No), "Would you recommend UPPP surgery to others?" (Yes/No/Do not Know), "Do you snore?" (Never/Sometimes/Often/Always), and "How would you estimate your daytime sleepiness compared to before UPPP surgery?” (Cured/Better/Unchanged).

B. Questionnaire concerning pharyngeal symptoms such as vivid queasy feelings, globus sensation, and trouble with swallowing (for details, see Lundkvist and Friberg(8)). The questionnaire has not been used previously on this cohort of OSAS patients. The 10 questions 
were answered on a four-point Likert scale in the order none, mild, moderate, severe, with a maximum symptom score of 30 .

C. The Epworth Sleepiness Scale (ESS),(12) used only at the 15-year follow-up.

Drop-out and subgroup analyses: Drop-outs were defined as patients not answering the 15year questionnaires. Further subgroups were Living or Deceased, as well as those who made sleep apnoea recordings or not.

\section{Ethical Considerations}

All patients gave their informed consent and the study was approved by the Swedish local Ethics Committee at Huddinge University Hospital, Stockholm (474/03).

\section{Statistics}

The following non-parametric statistical methods were used: Wilcoxon-matched pair tests (WMPTs) to compare the results before and after surgery; Mann-Whitney U tests (MWUTs) for unpaired tests of drop-out and subgroup analyses. Correlation analyses were performed using Spearman rank correlation tests (SRCTs). The software program Statistica 6.0 was used.

Standardized Mortality Ratio (SMR) Calculations: The cohort was followed from the date of surgery up to the date of death or December 31,2008, which ever occurred first. The expected mortality in the patient group was estimated by splitting the person years of follow-up according to the attained age in 5-year age bands and calendar years, and multiplying these by the corresponding sex-specific mortality rate in the general population. The overall and circulatory disease-specific mortality rates were obtained from the Swedish Cause of Death 
Register. The SMR was calculated by dividing the observed number of deaths by the expected number. The $95 \%$ confidence interval for the SMR was calculated assuming that the observed number of deaths follow a Poisson distribution.(13) 


\section{$\underline{\text { Results }}$}

The median follow-up time was 189 months (15.75 years) (range 183-219 months). At follow-up 13 patients (26\%) had died. Twenty-six of the 37 (70\%) living patients underwent postoperative sleep apnoea recordings. The median $\mathrm{ODI}_{4}$ had significantly decreased from 26.5 (range 4-82) to 8.5 (range 0-60), $p<0.01$, (WMPT); Figure 3. The mean $\mathrm{ODI}_{4}$ was reduced from 31.8 to 15.4 , a reduction of $52 \%$. Seventeen out of $26(65 \%)$ of the patients fulfilled the success criteria. Thirteen of these 17 patients were also classified as successes at the 4-year follow-up. The patient with a baseline $\mathrm{ODI}_{4}$ of 4 had at the 15-year follow-up an $\mathrm{ODI}_{4}$ of 34 , and was classified as failure.

Concerning objective snoring, 9 of 26 (35\%) were categorized as non-snorers. There was no correlation between subjective and objective snoring. However, a significant correlation between $\mathrm{ODI}_{4}$ and the percentage of objective snoring during the estimated TST was found: $p$ $<0.05(\mathrm{SRCT})$.

The median BMI was unchanged between baseline, $30(20-43) \mathrm{kg} / \mathrm{m}^{2}$, and 15 years, 30 (2242) $\mathrm{kg} / \mathrm{m}^{2}$

The questionnaires were answered by 32 of the 37 living patients ( $86 \%$ ). Twenty-five patients (78\%) were satisfied with the surgery, but four regretted it. Twenty-three patients (72\%) stated that they would recommend the surgery to another person. Concerning subjective snoring, two rated "never", 11 "sometimes", 11 "often", and 8 "always". Thus 13 out of 32 $(40 \%)$ rated "never" or "sometimes"; Figure 1. Ten patients rated that they were "cured" concerning EDS, 18 "better", and 4 patients were "unchanged" compared to baseline, thus 28 
of 32 (88\%) were "better" or "cured"; Figure 2. The median ESS value was 6 (range 0-19).

The median pharyngeal disturbances value after UPPP was 3 (range 0-10).

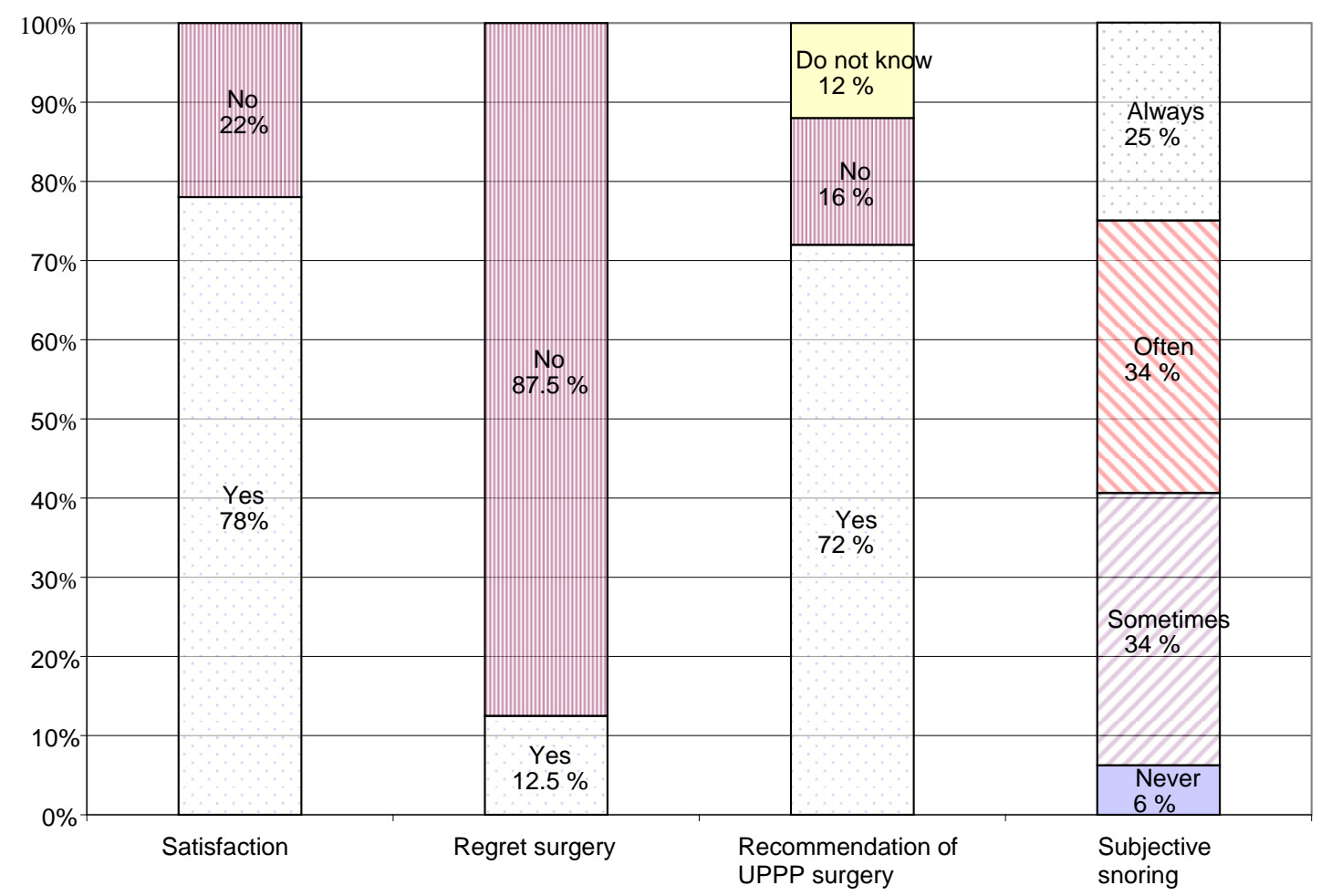

Fig. 1.

The proportion of satisfaction, regret and recommendation of uvulopalatopharyngoplasty (UPPP), as well as subjective snoring 15 years postoperatively. Number of patients=32.

Two patients underwent mandibular surgery (ISO, inferior sagittal osteotomy)(14) approximately 4 years after UPPP, one of which had died at the present follow-up, and one satisfied the success criteria. Six patients were treated with CPAP and one with MRD, i.e., altogether 8 patients had complementary treatment at the 15 -year follow-up. Five of these 8 (62\%) were still satisfied with UPPP, as well as rated themselves better concerning EDS. Their median 15-year $\mathrm{ODI}_{4}$ value was 19 (8-39). Among the patients without any complementary treatment $(n=24)$, the corresponding values were $20(83 \%)$ satisfied, 23 (96\%) had EDS improvement and their median 15-year $\mathrm{ODI}_{4}$ value was 5.5 (0-60). 
In the mortality analysis we had a prolonged observation period of, in total, 18.2 years up to

December 31, 2008, thus approximately 3 years extra observation time. We noted 18 deaths during a total of 908 person-years of follow-up. The expected number of deaths, assuming that this cohort had the same mortality as the general population, was calculated to be 13.6, corresponding to a standardized mortality ratio (SMR) of 1.32 (95\% CI: 0.78-2.09). Thus, no significantly elevated mortality compared to the general population could be observed. Ten of the deaths were due to circulatory diseases, yielding a cause-specific SMR of 1.72 (95\% CI: $0.83-3.17)$.

\section{Symptoms of excessive daytime sleepiness}

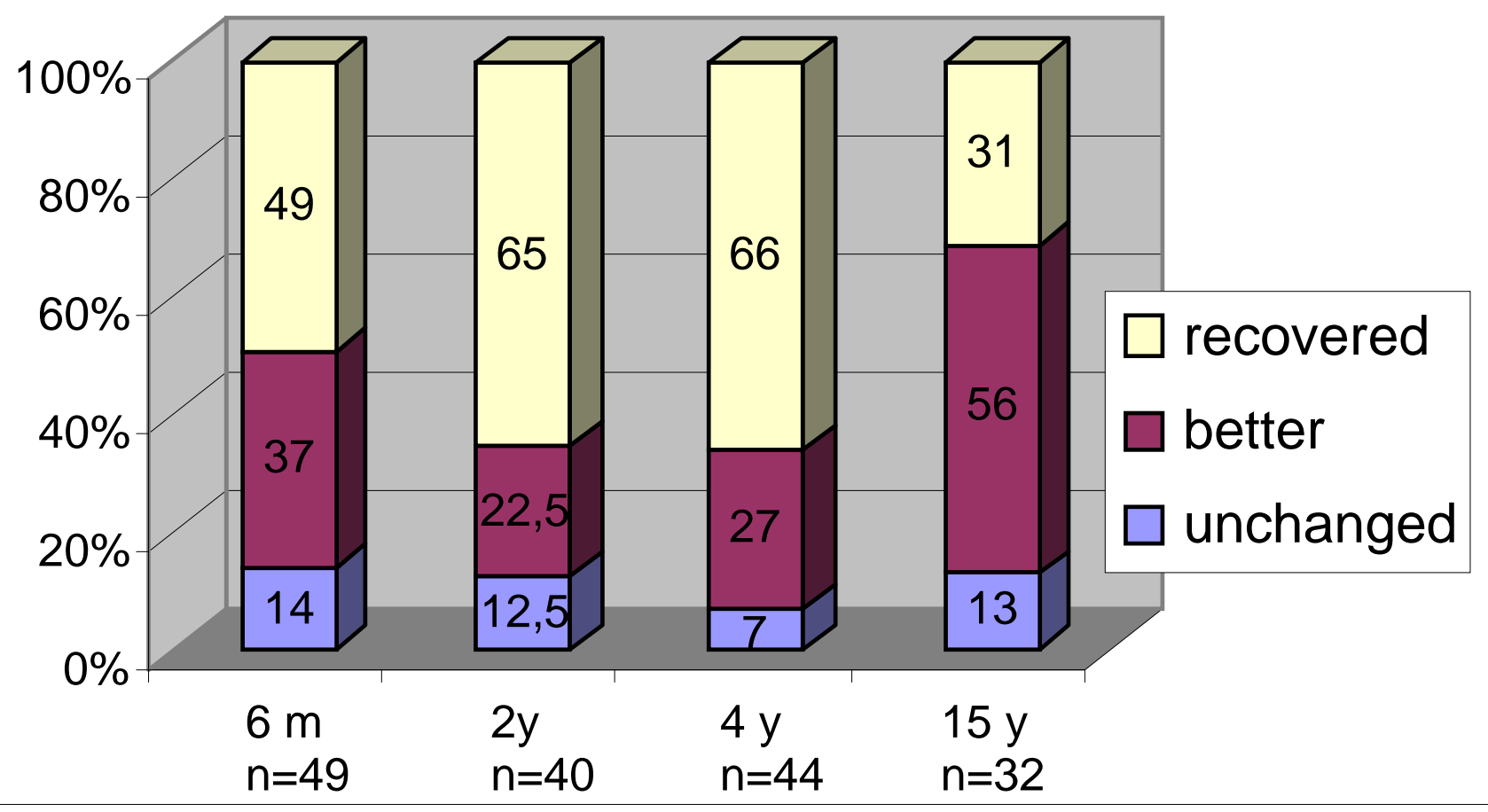

Fig. 2. The ratings of changes in excessive daytime sleepiness (EDS) among the included patients at evaluations after 6 months $(\mathrm{m})$ as well as after 2, 4 and now 15 years (y) after UPPP surgery for OSAS.

The drop-out rate for questionnaires was 14\%, and the analysis did not show any significant differences in baseline values for age, $\mathrm{BMI}, \mathrm{ODI}_{4}$, or nadir $\mathrm{SaO}_{2}$. However, the median age of 
the patients who dropped out was 9 years higher than that of those who filled out the questionnaires; Table I. The following subgroup analyses were made: between Living and Deceased and between those making sleep recordings or not. The only significant difference was in the median age of Living and Deceased: $p<0.05$, MWUT; Table I. The deceased patients were at baseline in median 9 years older than the living ones. Furthermore, analyses were also made of the postoperative $\mathrm{ODI}_{4}$ values at 6 months and 2, 4, and 15 years between Living and Deceased, and between the patients who made sleep recordings and who did not, which showed small and non-significant differences; MWUT, Table II.

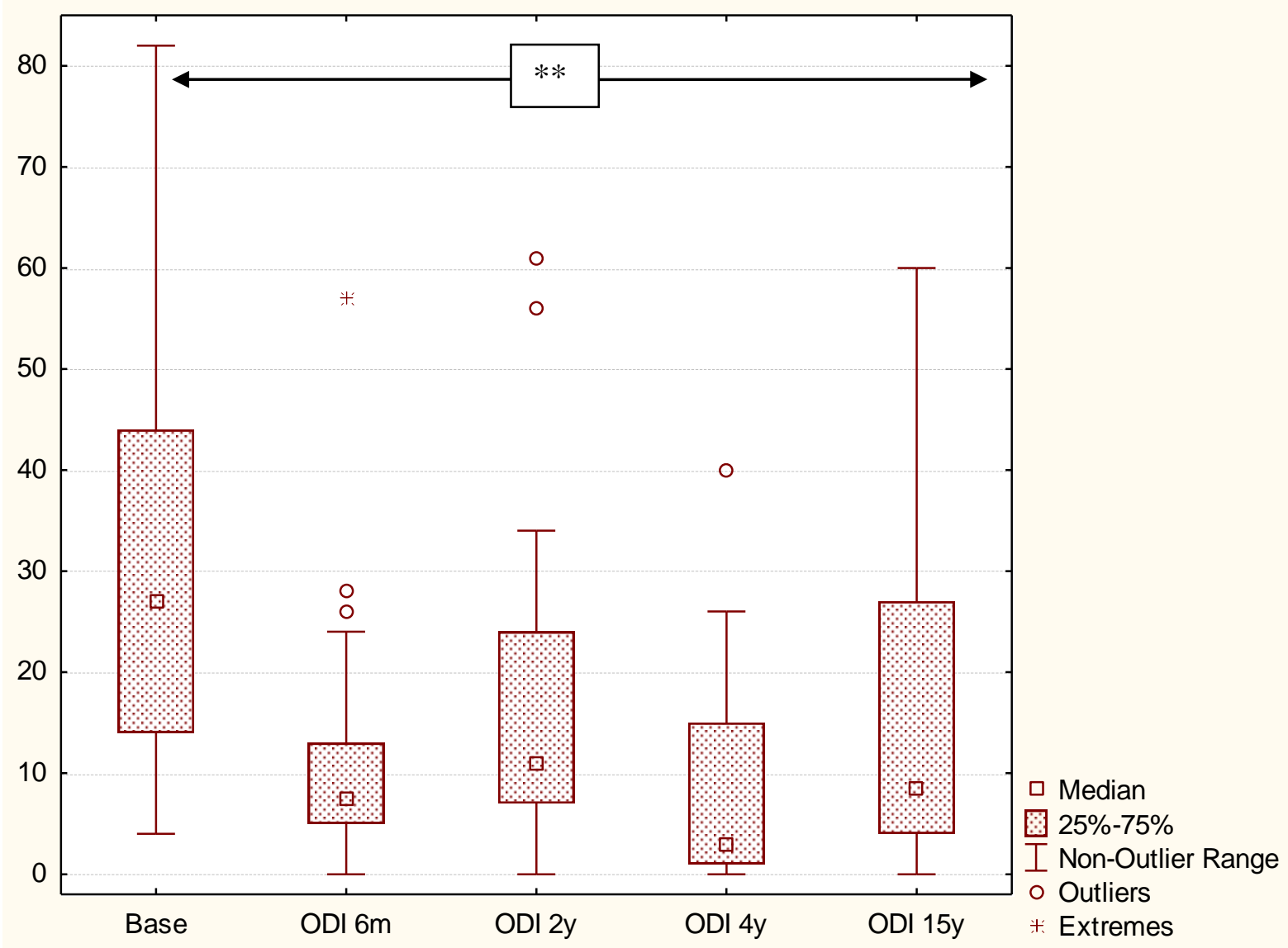

Fig. 3. Box-plots showing the oxygen desaturation index $4 \%\left(\mathrm{ODI}_{4}\right)$ values in the 26 patients who performed sleep recordings, at baseline and different follow-ups; 6 months, 2, 4 and 15 years. Note the significant difference between baseline and 15 years in ODI, ${ }^{* *} p<0.01$ (WMPT). 


\section{Table II}

Postoperative $\mathrm{ODI}_{4}$ values after 6 months, 2, 4 and 15 years

in all patients, also divided into subgroups

\begin{tabular}{lccccc}
\hline & All & Living & Dead & $\begin{array}{c}\text { Sleep } \\
\text { recordings }\end{array}$ & $\begin{array}{c}\text { No sleep } \\
\text { recordings }\end{array}$ \\
ODI $_{4} 6$ months & $8(0-57) n=50$ & $8(0-57) n=37$ & $5(0-47) n=12$ & $8(0-57) n=26$ & $11(0-39) n=11$ \\
ODI $_{4}$ 2 years & $11(0-65) n=49$ & $12(0-65) n=34$ & $10(6-56) n=11$ & $11(0-61) n=25$ & $15(0-65) n=9$ \\
ODI $_{4} 4$ years & $6(0-59) \mathrm{n}=48$ & $5(0-59) \mathrm{n}=36$ & $7(1-56) \mathrm{n}=9$ & $3(0-40) \mathrm{n}=25$ & $7(1-59) \mathrm{n}=11$ \\
ODI $_{4}$ 15 years & $9(0-60) \mathrm{n}=26$ & $9(0-60) \mathrm{n}=26$ & & $9(0-60) \mathrm{n}=26$ & \\
\hline
\end{tabular}

Values are in median and range. $\mathrm{ODI}_{4}=$ Oxygen Desaturation Index $4 \%$ 


\section{Discussion}

The main finding of this 15-year follow-up after UPPP was a stable and significant decrease in median $\mathrm{ODI}_{4}$ values over the years. Objectively, approximately two thirds of the patients were successfully treated (65\% fulfilled $\mathrm{ODI}_{4}$ success criteria). Subjectively, a majority had improved/cured EDS (88\%), and was satisfied (78\%). Approximately one third experienced a good effect on subjective (40\%), as well as objective (35\%), snoring. Also, the mortality rate of this OSAS group did not significantly differ from the corresponding mortality rate in the general Swedish population.

As reported earlier by Larsson et al.,(4)'(5) the success rate for respiratory parameters was 30 out of 50 patients $(60 \%)$ after 6 months, 19 out of $49(39 \%)$ after 2 years, and 24 out of 48 (50\%) after 4 years. At this 15-year follow-up it was 17 out of $26(65 \%)$. Our research group has followed another cohort of 158 OSAS patients one year after UPPP, using the same success criteria and surgical method, and finding a very similar success rate of 64\%.(15) This can be compared with another long-term study with a $48 \%$ success rate after $4-8$ years.(6) It is important to note that the researchers in that study used another outcome parameter (AHI) and stricter criteria ( $<10$ and $50 \%$ reduction). Similarly, our result of a $52 \%$ reduction in the mean $\mathrm{ODI}_{4}$ is somewhat difficult to compare with the meta-analysis of 15 UPPP studies with 950 patients, showing a $33 \%$ reduction in the mean AHI.(2) However, our results may be an indication that we are, at least well in line with other centres.

The most important finding in this study is that neither the objective (sleep recordings) nor the subjective results deteriorated over time, as has been suspected. A decrease in BMI does not seem to be an explanation, since median BMI did not change. We were positively surprised 
that these patients kept their weight, which might be explained by our clinical practice; to inform all patients of the importance of stable weight after surgery. One reason for the positive result concerning symptoms could be that the prevalence levels of OSAS has been known to decrease in older ages,(16) at least in males, which was the predominant gender (96\%) in our study population.

The efficacy role of UPPP in OSAS treatment has been questioned because there have been very few randomized studies. In a 4-year follow-up of a randomized trial of MRD and UPPP, Walker-Engström et al. concluded that the MRD group showed a significantly higher success rate regarding the apnoea index compared to the UPPP group, i.e., $81 \%$ compared to $53 \%$, but that the effectiveness of the MRD was invalidated by the compliance rate of only $62 \% .(17)$

In the present study, there was a surprisingly high satisfaction rate and few regrets, considering the very long follow-up period, which may reflect the fact that the majority of the patients considered themselves improved in their symptoms. However, the success level for snoring was lower, but this did not seem to influence the satisfaction rating. Also, even among the patients who had complementary treatment (ISO, CPAP, or MRD), the majority were satisfied with the surgery.

The postoperative pharyngeal symptoms were few. Our group has previously evaluated the results for UPPP patients both preoperatively and postoperatively.(8) There were no increased rating of pharyngeal symptoms postoperatively, with an unchanged median value of 5 . However, in a non-snoring age-, BMI- and gender-matched control group, the median value was only 1, indicating a certain amount of discomfort already before surgery in OSAS patients. There have been reports of large proportions of dysphagia and globus sensation in 
UPPP patients,(7) but the surgical techniques have changed over time, making such reports confusing. In many cases a mixture of methods has been used and the reports are therefore difficult to interpret. However, at our centre, a conservative technique using cold steel with a one-stage procedure has been employed throughout the years.

The standardized mortality ratios indicated no increased mortality in this OSAS population compared to the general population in Sweden. There are several studies indicating an approximately 3 times increased mortality associated with severe untreated OSAS.(10)' (11) Our study population was heterogeneous, including all degrees of OSAS, obesity and cardiovascular comorbidity. UPPP was practically the only available treatment for OSAS at the time, and it was offered to all who did not have any major contraindication for surgery, explaining the heterogeneity in our population. The reason for our low mortality rates could be explained by the fact that several patients were treated with CPAP and MRD at least in periods if the UPPP treatment had failed, and two patients had complementary mandibular surgery. Another reason could be a protective effect of UPPP, as suggested by other authors.(9) However from our small and heterogeneous population it is difficult to draw such conclusions. In addition, Lavie et al. have suggested a protective role of having moderate OSAS at higher ages, possibly by the mechanism that apnoea during sleep may activate adaptive pathways so that chronic intermittent hypoxia may be cardioprotective.(16)

There are several weaknesses in this study: firstly, the lack of a randomized control group, and, secondly, a 15-year recall bias. Thirdly, there were a relatively small number of patients who underwent the 15-year follow-up sleep apnoea recording, only 26 of the originally included 50 patients. However, the very long follow-up quite naturally explains that 11 patients did not show up and that 13 were deceased. In addition, the subgroup analyses only 
showed small and non-significant differences, except between the living and deceased concerning age. The deceased patients were at baseline 9 years older than the living ones, which may reflect age as a natural cause of death. Altogether, the subgroup analyses indicated quite homogeneous groups at baseline, as well as stable and equal postoperative results of the sleep recordings throughout the years for all subgroups. Fourthly, the sleep apnoea recordings have clear weaknesses compared to the technology of today, since the AHI parameter was not measured. During the 1980s, the available measuring technique with thermistors was not considered reliable in ambulatory monitoring. However, it is possible that oxygen desaturations have a greater impact on cardiovascular health than apnoeas/hypopnoeas; for example, Baguet et al. found that indices of oxygen desaturation were associated with carotid wall hypertrophy and carotid plaques, while other respiratory indices were not.(18) Fifthly, there was no washout period for the 6 patients with CPAP and one with MRD, so a remaining effect of these complementary treatments could have affected the outcomes in these patients, which could also be the case for the patient who had undergone ISO. However, the subjective outcome did not show any major differences. In the sleep apnoea recordings, the $\mathrm{ODI}_{4}$ was higher than in the group without complementary treatment, which was expected. Other studies have shown that the majority of apnoeas relapse already during the first night without CPAP.(19)

The most important strength of this study is the very long-term follow-up including sleep recordings. Furthermore, the majority of these patients have undergone four different followups over the years, which enabled us to show consistency in the results from sleep recordings. Also, considering the time period, the drop-out rate of the subjective measurement was quite low (14\%). Lastly, the Swedish social security number register makes it possible to follow the study population's mortality rates and causes and to keep updated address records. 


\section{Conclusions}

This 15 year follow-up after UPPP, the longest hitherto performed, showed a stable and significant decrease in median $\mathrm{ODI}_{4}$ values throughout the years. Objectively, approximately two thirds of the patients fulfilled the success criteria $\left(\mathrm{ODI}_{4}\right.$ reduction of $50 \%$ and $\left.<20\right)$. Subjectively, a vast majority had improved/cured EDS and was satisfied. No increased mortality rate was seen compared to the general Swedish population. 


\section{References}

1. Fujita S, Conway W, Zorick F, Roth T. Surgical correction of anatomic azbnormalities in obstructive sleep apnea syndrome: uvulopalatopharyngoplasty. Otolaryngol Head Neck Surg. 1981 Nov-Dec;89(6):923-34.

2. Caples SM, Rowley JA, Prinsell JR, Pallanch JF, Elamin MB, Katz SG, et al. Surgical modifications of the upper airway for obstructive sleep apnea in adults: a systematic review and meta-analysis. Sleep. 2010 Oct 1;33(10):1396-407.

3. Sher AE, Schechtman KB, Piccirillo JF. The efficacy of surgical modifications of the upper airway in adults with obstructive sleep apnea syndrome. Sleep. 1996 Feb;19(2):156-77.

4. Larsson H, Carlsson-Nordlander B, Svanborg E. Long-time follow-up after UPPP for obstructive sleep apnea syndrome. Results of sleep apnea recordings and subjective evaluation 6 months and 2 years after surgery. Acta Otolaryngol. 1991;111(3):582-90.

5. Larsson LH, Carlsson-Nordlander B, Svanborg E. Four-year follow-up after uvulopalatopharyngoplasty in 50 unselected patients with obstructive sleep apnea syndrome. Laryngoscope. 1994 Nov;104(11 Pt 1):1362-8.

6. Janson C, Gislason T, Bengtsson H, Eriksson G, Lindberg E, Lindholm CE, et al. Long-term follow-up of patients with obstructive sleep apnea treated with uvulopalatopharyngoplasty. Arch Otolaryngol Head Neck Surg. 1997 Mar;123(3):257-62. 7. Franklin KA, Anttila H, Axelsson S, Gislason T, Maasilta P, Myhre KI, et al. Effects and side-effects of surgery for snoring and obstructive sleep apnea--a systematic review. Sleep. 2009 Jan 1;32(1):27-36.

8. Lundkvist K, Friberg D. Pharyngeal disturbances in OSAS patients before and 1 year after UPPP. Acta Otolaryngol. 2010 Dec;130(12):1399-405. 
9.

Lysdahl M, Haraldsson PO. Long-term survival after uvulopalatopharyngoplasty

in nonobese heavy snorers: a 5- to 9-year follow-up of 400 consecutive patients. Arch Otolaryngol Head Neck Surg. 2000 Sep;126(9):1136-40.

10.

Marin JM, Carrizo SJ, Vicente E, Agusti AG. Long-term cardiovascular outcomes in men with obstructive sleep apnoea-hypopnoea with or without treatment with continuous positive airway pressure: an observational study. Lancet. 2005 Mar 1925;365(9464):1046-53.

11. Young T, Finn L, Peppard PE, Szklo-Coxe M, Austin D, Nieto FJ, et al. Sleep disordered breathing and mortality: eighteen-year follow-up of the Wisconsin sleep cohort. Sleep. 2008 Aug 1;31(8):1071-8.

12. Johns MW. A new method for measuring daytime sleepiness: the Epworth sleepiness scale. Sleep. 1991 Dec;14(6):540-5.

13. Breslow NE, Day NE. Statistical methods in cancer research. Volume II--The design and analysis of cohort studies. IARC Sci Publ. 1987(82):1-406.

14. Riley RW, Powell NB, Guilleminault C, Nino-Murcia G. Maxillary, mandibular, and hyoid advancement: an alternative to tracheostomy in obstructive sleep apnea syndrome. Otolaryngol Head Neck Surg. 1986 Jun;94(5):584-8.

15. Lundkvist K, Januszkiewicz A, Friberg D. Uvulopalatopharyngoplasty in 158 OSAS patients failing non-surgical treatment. Acta Otolaryngol. 2009 Nov;129(11):1280-6. 16. Lavie P, Lavie L. Unexpected survival advantage in elderly people with moderate sleep apnoea. J Sleep Res. 2009 Dec;18(4):397-403.

17. Walker-Engstrom ML, Tegelberg A, Wilhelmsson B, Ringqvist I. 4-year followup of treatment with dental appliance or uvulopalatopharyngoplasty in patients with obstructive sleep apnea: a randomized study. Chest. 2002 Mar;121(3):739-46. 
18. Baguet JP, Hammer L, Levy P, Pierre H, Launois S, Mallion JM, et al. The severity of oxygen desaturation is predictive of carotid wall thickening and plaque occurrence. Chest. 2005 Nov;128(5):3407-12.

19. Phillips CL, Yang Q, Williams A, Roth M, Yee BJ, Hedner JA, et al. The effect of short-term withdrawal from continuous positive airway pressure therapy on sympathetic activity and markers of vascular inflammation in subjects with obstructive sleep apnoea. $\mathbf{J}$ Sleep Res. 2007 Jun;16(2):217-25. 